\title{
A PRODUCTIVITY MEASUREMENT MODEL FOR HIGHER EDUCATIONAL INSTITUTIONS
}

\author{
S.A. Oke \\ Department of Mechanical Engineering \\ University of Lagos, Nigeria \\ sa_oke@yahoo.com
}

\begin{abstract}
Introduced several decades ago, productivity has rapidly developed into a powerful and versatile tool for both service and manufacturing sectors. Service represents the largest and fastest growing sector of developing economies. Yet, issues surrounding performance measurement in higher education institutions (HEI) presents an interesting and important research challenge often ignored. Rapid advances made during the past decade on problems associated with productivity have brought into an ever-sharper focus the need for a comprehensive and competent treatment of service productivity in HEI. The need for a treatment of this type has been long felt in research institutions, governments, and universities. This work investigates the feasibility of measuring the productivity of an academic department of a university using the NPC/NIIE model.
\end{abstract}

\section{OPSOMMING}

Produktiwiteitsmeting het oor die afgelope dekades snel ontwikkel tot ' $n$ kragtige alomtoepaslike gereedskap vir die diens- en vervaardigingsektore. Die meet van produktiwiteit van dienslewering by hoër onderwysinstansies is ' $n$ navorsingsuitdaging wat dikwels onaangeraak gelaat word. Ontwikkelings op die gebied van produktiwiteitsmeting beklemtoon die belangrikheid van die bogenoemde vraagstuk. Die resultate van die studie is bemoedigend. Onder andere toon dit hoedat produktiwiteitsdoelwitte bereik kan word en hoedat potensiële probleemareas aangespreek behoort te word. 


\section{INTRODUCTION}

The productivity literature abounds with diverse research on methodologies, empirical studies, cases, and conceptual work that improve our theoretical understanding of performance issues $[9,7,10]$. Research efforts have however been directed at service productivity in a variety of domains such as economics, construction, and industrial engineering, among others $[12,13]$. Unfortunately, one of the fundamental areas of service is least explored. Performance measurement in higher education institutions presents an interesting and important research area yet ignored [2, 3, 8, 6, 5]. The education sector is important since a substantial part of the national budget is allocated to education yearly. Yet, it is a common belief that higher education institutions in West Africa are wasting resources. It is therefore, necessary to measure how effectively and efficiently these institutions utilise resources. Clearly, productivity indices will indicate how well the resources are utilised by higher education institutions to achieve primary objectives.

Consider the case of a particular university, for instance. Every year, a substantial amount of the budget goes for the salary of both academic and non-academic staff, goods and services, and capital development projects. Unfortunately, an independent instrument for measuring how well these resources are utilised or how setout objectives are realised in the West African institutional context is lacking. Like manufacturing industries, a productivity measurement model may be one of the most effective means by which the performance of higher education institutions can be measured. It will enable university administrators to monitor periodically how well faculties, departments, and possibly individuals are performing using a set of resources. It will also be possible to compare the performance of any two or more departments, faculties, colleges or universities. A productivity model will provide a scientific basis for the Federal Governments of West African countries to control resources for higher education institutions. By stating productivity targets, institutions whose periodic productivity falls below target may have to explain.

Any fall in productivity suggests some questionable use of resources or poor performance in output. Using a productivity measurement model, the specific cause(s) of poor performance may be traced. From the on-going discussion it should be obvious that the administration of higher education institutions will be made easier with information from a productivity measurement model. The mere knowledge that their performance is being monitored or measured will compel the personnel of higher educational institutions to be cautious with the use of resources. Such personnel are more likely to pursue education objectives with greater zeal once achievement can be measured in terms of various input and output resources.

Clearly, over the last several years, the measurement of academic institution's productivity has generated increasing attention as a strategic means to enhance productivity and economic growth. Several research documentations all identify productivity measurement as an important contribution to academic institution's economic and social well being $[14,15,16]$. The heightened recognition of the importance of productivity measurement in higher education institutions has led universities, governments and the private sector to call for more support, and greater success, in its evaluation.

Despite the importance of measuring the productivity of higher education institutions, actual measurement of any institution in West Africa, has not been reported in the literature. The one 
suggested by the National Productivity Centre (NPC) and the Nigerian Institute of Industrial Engineers (NIIE) has no real life example to show how it would be used. Mention was made of using the grade points of students as the output. Also, nothing was said about the particular types of inputs that will be used. It is therefore the objective of this work to investigate the feasibility of measuring the productivity of a university. In particular, an attempt will be made to identify quantifiable input and output resources of a university for measuring productivity. These quantities will then be used to test the NPC/NIIE model using an academic department.

\section{OVERALL ASPECTS OF STUDY}

The output of higher education institutions, say a university, may be the amount of learning carried out by the students, the value of identifiable research, and the amount of community services by the lecturers (see figure 1 ).

There are four measurement techniques suggested for measuring output. These are (1) tangible output technique, (2) tangible output in plan period, (3) checklist indicators and (4) composite index. The technique considered most appropriate in this study is the tangible output approach since the output of a university can be quantified. Detailed examination of the possible output of a university reveals that it can be of three types - (1) the load and performance of students, (2) output of lecturers and research activities and (3) university contribution to community.

In view of time and resource constraints, only one type of output of the university vis-à-vis the training of students is pursued in this study. For this output type, two distinct methods were identified. The first considers course units as the quantity and grade as unit value (price). The value of output is therefore the weighted grade point. The second method considers course units as the quantity and prices in terms of school fees.

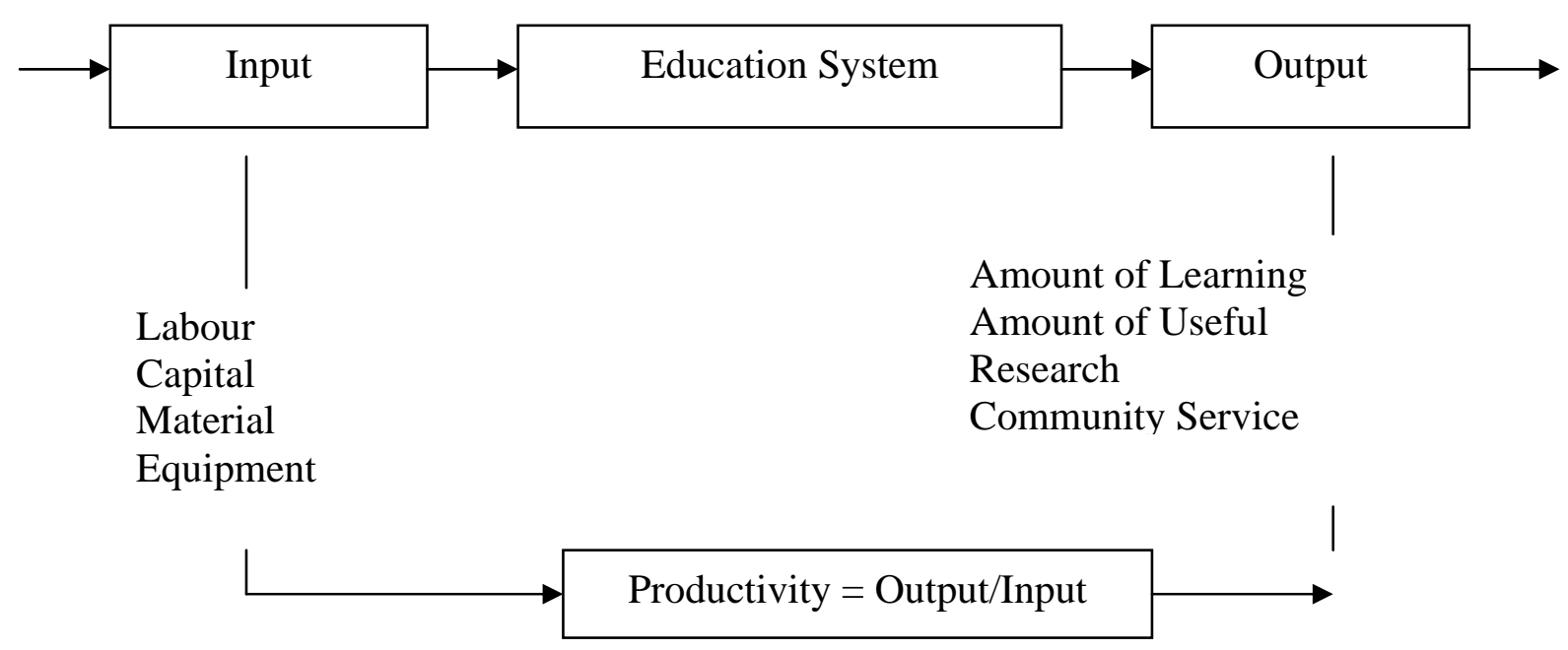

Figure 1: Higher Education Institution Productivity Model

The input resources will include labour, capital, material and other expenses. Labour is made up of actual salaries and fringe benefits of both academic and non-academic staff. Their fringe 
benefits include leave and housing allowances and allowances due to journals, membership of learned societies and examination allowances. The labour input consists of academic staff (comprising senior members) and non-academic staff (senior and junior members). The senior staff (academics) includes the head of department and other lecturers while the senior staff (non-academic) is composed of technologists and secretaries. The junior staff could be further classified as artisans, clerical officers, drivers and office assistants. For materials, we have stationeries, chalks, dusters and other teaching aids/writing materials supplied by the university. Capital includes inventory, investment, building construction and maintenance, laboratory machinery and equipment. Other expense input is classified into travelling, information processing, telephone, e-mail, fax and electricity costs.

\section{THE NPC/NIIE PRODUCTIVITY MEASUREMENT MODEL}

The originality of the NPC/NIIE productivity measurement model (developed for the National Productivity Centre (NPC) and the Nigerian Institute of Industrial Engineers (NIIE)) belongs to Charles-Owaba [4]. In applying this model to higher education institutions, an overview of the model supported by some key terms used in the model is presented. What then follows is the format of the model.

\subsection{Overview}

The goal of this sub-section is to present the NPC/NIIE model used to solve productivity measurement problems. The use of the model is appropriate since it could be used to monitor the current level of productivity and also has the potential for future performance measurement. With the target component included in the model, an adequate feedback on performance is guaranteed. A starting point here is the definition of some key terms. These are defined as follows:

$\begin{array}{ll}\text { Base period (BP) } & \begin{array}{l}\text { Plan period whose productivity is considered as an ideal with which } \\ \text { productivity of future periods can be compared. }\end{array} \\ \text { Current period (CP) } & \begin{array}{l}\text { Plan period whose productivity is being measured. } \\ \text { Quantitative value of a set of goals of an organisation or a subsection. } \\ \text { Output }\end{array} \\ \text { Input } & \begin{array}{l}\text { Quantitative value of a set of resources used to realize the output of } \\ \text { an organisation or a subsection of an organisation. }\end{array}\end{array}$

Static Productivity (SP): This is a snapshot assessment of the performance of an academic faculty, department or individual lecturers. The values obtained from this measure may reflect the current effort and progress made by deans of faculties or departmental heads towards effective administration of faculties and the departments of the universities. It is obvious that academic progress in publications may be stimulated by funds availability to support page charges and conference attendance fees for scholars. Getting financial support from the department largely depend on the budget statement prepared by the head of department. So if a lean budget is prepared then attendance of conferences by academic staff may be restricted to personal sponsorship. This then becomes a counter-productive issue that may demotivate academic staff from publishing. Publishing also depends on the ability of group leaders to source for grants. These may have a direct influence on productivity measures. 
Dynamic Productivity (DP): In measuring the dynamic productivity in an educational system our interest is to relate the performance in one academic session to another. The picture shown here compares differences in performance of the various academic staff within the department. For example we are able to understand if promotions to the next level of advancement is justified scientifically. For example, a senior lecturer promoted to the level of professor is expected to demonstrate professorial competence in terms of number of publications and teaching quality. If the changes in performance for the two periods do not justify the promotion, the professorial competence may be questioned.

Partial Dynamic Productivity (PDP): The relevance of partial dynamic productivity lies in its ability to reflect the performance of some partial factors that the researcher may be interested in knowing. Take the labour input for instance; one may be interested in knowing the performance of lecturers by publications. This is a partial factor since it only represents one part of the lecturer's job. One may make further probing into what category of publication has earned the lecturer being evaluated the particular mark. Is it journal publications, conference proceedings, book publishing, writing of monographs or unpublished reports? If further developed, proper empirical values for these items could be obtained. At this stage, we could also integrate the concepts of analytical hierarchy process (AHP), Pareto analysis or some other decision sciences prioritizing tools.

Total Dynamic Productivity (TDP): This gives a total picture of performance tracking from one period to another. It reflects the collective performance of the whole department or faculty as the case may be. The results from this observation may be helpful to the central administration in taking decisions on funds disbursement. Departments of high productivity may have to receive more recognition and funds than those with lower values of productivity.

At this stage it is appropriate to describe the procedure for model application.

\subsection{Model Application Procedure}

A step by step procedure of applying the model in any situation is shown as follows:

Step 1: Select a base period (once selected for a particular output, the base period remains unchanged).

Step 2: Identify each independent final output

Step 3: For each output identify the following:

a. Quantity of output in current period (CP)

b. Quantity of output in base period (BP)

c. Selling price of output in BP

d. Selling price of output in CP

e. Quantity of each individual input type in CP

$\mathrm{f}$. Cost price of each individual input type in $\mathrm{CP}$

g. Quantity of each individual input type in BP

h. Cost price of each individual input type in BP. 
Step 4: Compute the percentage change in:

1. Profitability for each resource type as well as total.

2. Productivity for each resource type as well as well as total.

3. Price recovery for each resource type as well as the total.

Step 5: Compute the effect of change of profitability, productivity and price recovery on savings ( ) for total and all input resources.

Step 6: Present the information collected or generated from step 2 to 5 in the format shown in table 1 for each independent service of the organisation.

Table 1 shows the format of the NPC/NIIE model. Other quantities traditionally measured together with productivity are profitability and price recovery factors. The former is a measure of change of revenue relative to the unit cost of operating while the later depicts the inflationary factor of performance.

\begin{tabular}{|c|c|c|c|c|c|c|c|c|c|c|c|c|c|c|c|}
\hline \multirow[b]{2}{*}{ Resource Description } & \multicolumn{3}{|c|}{$\begin{array}{c}\text { Current } \\
\text { period (CP) }\end{array}$} & \multicolumn{3}{|c|}{$\begin{array}{l}\text { Base } \\
\text { period } \\
\text { (BP) }\end{array}$} & \multicolumn{3}{|c|}{$\begin{array}{l}\text { Performance } \\
\text { ratio }\end{array}$} & \multicolumn{3}{|c|}{ \% change in } & \multicolumn{3}{|c|}{$\begin{array}{l}\text { Effect of } \\
\text { change }\end{array}$} \\
\hline & 1 & 2 & 3 & 4 & 5 & 6 & 7 & 8 & 9 & 10 & 11 & 12 & 13 & 14 & 15 \\
\hline \multicolumn{16}{|l|}{ Output } \\
\hline \multicolumn{16}{|l|}{ Undergraduate } \\
\hline \multicolumn{16}{|l|}{ Postgraduate } \\
\hline \multicolumn{16}{|l|}{ Total Output } \\
\hline \multicolumn{16}{|l|}{ Input } \\
\hline \multicolumn{16}{|l|}{ Materials } \\
\hline \multicolumn{16}{|l|}{ Labour } \\
\hline \multicolumn{16}{|l|}{ Capital } \\
\hline \multicolumn{16}{|l|}{ Others } \\
\hline Total Input & & & & & & & & & & & & & & & \\
\hline
\end{tabular}

\section{Table 1: Format of the NPC/NIIE Model}

The following is the interpretation of table 1 , which contains all the measurement information concerning productivity, profitability and price recovery factor.

1. The rows indicate specific resources whose productivity is to be measured

2. Columns 1 - 6: the service data i.e. quantities of output/inputs and their respective prices; columns $1-3$ for the $\mathrm{CP}$, and columns $4-6$ for the BP.

3. Columns $7-15$ : the result of the productivity measurement model. A value of ratio less than 1 reflects poor performance while 1 shows no change in performance relative to a $\mathrm{BP}$, a value greater than 1 shows an improvement.

4. Columns $10-12$ : (\%) growth in performance in the CP relative to the BP.

5. Column 10: the (\%) growth in profit in the proportion contributed by any specific resources.

6. Column 11: (\%) growth in productivity (utilization of resources). 
7. Column 12: the (\%) growth in price recovery factor, i.e. the effect of inflation on company operations.

8. Columns 13-15: the Naira contribution to change in savings due to productivity and price recovery.

9. Column 13: the combined (productivity and price changes) effect (in Naira) on change in profit or savings with respect to any input resources.

10. Column 14: (in Naira) the effect on change in profit or savings due to productivity alone.

11. Column 15: (in Naira) the effect due to price recovery on changes in profits.

It should be noted that columns $7-15$ are only shown as a guideline in the computation process. No efforts have been made to apply the calculation of these columns in this work. However, the author believes that it would serve useful information for future productivity modellers, hence the need for their inclusion in the paper.

Before discussing the model in more detail, the notations that are used in the model will briefly be explained. The notations and definitions used in the NPC/NIIE model are as stated below:

$\begin{array}{ll}\mathrm{a}_{\mathrm{ij}} & \text { Unit price of output } \mathrm{i} \text { in period } \mathrm{j} \\ \mathrm{b}_{\mathrm{ij}} & \text { Unit cost of input } \mathrm{i} \text { in period } \mathrm{j} \\ \mathrm{O}_{\mathrm{ij}} & \text { Quantity of output } \mathrm{i} \text { in period } \mathrm{j} \\ \mathrm{I}_{\mathrm{ij}} & \text { Quantity of input } \mathrm{i} \text { in period } \mathrm{j} \\ \mathrm{n} & \text { Total number of output } \\ \mathrm{m} & \text { Total number of input } \\ \mathrm{j} & \text { Period of productivity measurement } \\ \mathrm{SP} & \text { Static Productivity } \\ \mathrm{DP} & \text { Dynamic Productivity } \\ \text { TDP } & \text { Total Dynamic Productivity } \\ \text { PDP } & \text { Partial Dynamic Productivity }\end{array}$

Note: Naira is the official currency of Nigeria, $\$ 1=125$ Naira (or 125)

\subsection{Model Formulation}

The model presented here relates to four measuring parameters: static productivity, dynamic productivity, total dynamic productivity, and partial dynamic productivity. These are expressed as equations (1) to (4) as follows:

$$
\begin{aligned}
& S P=\frac{\sum_{i=1}^{n} a_{i j} o_{i j}}{\sum_{i=1}^{m} b_{i j} I_{i j}} \\
& D P=\frac{\text { Static Productivity of CP }}{\text { Static Productivity of BP }}
\end{aligned}
$$




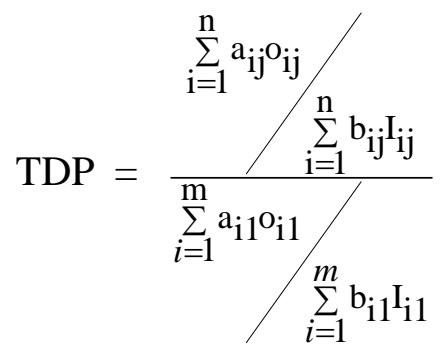

$$
\text { PDP }=\frac{\sum_{\mathrm{i}=1}^{\mathrm{n}} \mathrm{a}_{\mathrm{ij}} \mathrm{o}_{\mathrm{ij}} / \sum_{\mathrm{i}=1}^{\mathrm{n} \mathrm{a}_{\mathrm{i} 1} \mathrm{o}_{\mathrm{i} 1}}}{\mathrm{~b}_{\mathrm{ij}} \mathrm{I}_{\mathrm{ij}} / \mathrm{b}_{\mathrm{i} 1} \mathrm{I}_{\mathrm{i} 1}}
$$

In the determination of TDP, the current period is designated by $\mathrm{j}$, while the base period is fixed as the first period under consideration. This is the basis of computation of PDP also. The PDP reflects changes in the value of the output relative to the base period to changes in the value of the input relative to the base period.

\section{DATA COLLECTION AND ANALYSIS PHASE}

The data collection and analysis section discusses the procedure for data collection and the major analysis carried out in the work. The analysis includes a close investigation into the base period concept. This is shown in the various tables presented with supporting comments thereafter. An additional part of the analysis is the investigation into the changes in input and output values. The input values are considered on individual components: materials, labour, capital, and other expenses. The output is considered in totality.

\subsection{Data Collection Procedures}

The data were collected from an academic department of a West African university, in particular, Nigeria. The department was established in 1980 for the purpose of being a centre for sound judgements and correct knowledge in the field of engineering. The data was for a period of four sessions and classified as input and output. The data on labour input were obtained from the estimates of budget allocation. The data for material input, obtained from the imprest account gives the amount for each type of material consumed per month. Data on capital and other expense input were obtained from the acquired equipment record file and the imprest account book respectively (see table 1). For the output data, marks on performance of students in various courses were collated from the examination records. The two suggested output types (Methods 1 and 2) are shown in tables 2 and 3 respectively. Method 1 is the situation where school fees are charged for both undergraduate and postgraduate students. However, Method 2 reflects a situation in which school fees are not charged. It is important to distinguish these methods since each method is appropriate for a specific situation. It depends on the environment in which the measurement of productivity is to be carried out. Nigeria is a good example. In the country two categories of universities exist: one in which school fees are paid, the other in which school fees are not paid. 


\begin{tabular}{lcccccccc}
\hline Resource Description & \multicolumn{2}{c}{ Session 1 } & \multicolumn{2}{c}{ Session 2 } & \multicolumn{2}{c}{ Session 3 } & \multicolumn{2}{c}{ Session 4 } \\
\hline & $\begin{array}{l}\text { Qty } \\
\text { (Weighted grade }\end{array}$ & $\begin{array}{c}\text { Qty } \\
\text { (Weighted grade }\end{array}$ & $\begin{array}{c}\text { Price } \\
\text { point) }\end{array}$ & \multicolumn{2}{c}{$\begin{array}{c}\text { Qty } \\
\text { point) }\end{array}$} & \multicolumn{2}{c}{$\begin{array}{c}\text { Price } \\
\text { point) }\end{array}$} & $\begin{array}{c}\text { Qty } \\
\text { Price } \\
\text { (Weighted grade } \\
\text { point) }\end{array}$ \\
\cline { 2 - 10 } Post graduate students & 1171 & 1.0 & 941 & 1.0 & 1158 & 1.0 & 1704 & 1.0 \\
Under graduate students & 1584 & 1.0 & 2671 & 1.0 & 3414 & 1.0 & 4561 & 1.0 \\
\hline
\end{tabular}

Table 2: Output Data (Method 1)

\begin{tabular}{lccccccccc}
\hline Resource Description & \multicolumn{2}{c}{ Session 1 } & \multicolumn{2}{c}{ Session 2 } & \multicolumn{2}{c}{ Session 3 } & \multicolumn{2}{c}{ Session 4 } \\
\hline & Qty & Price & Qty & Price & Qty & Price & Qty & Price \\
& (Units) & (N/unit) & (Units) & (N/unit) & (Units) & (N/unit) & (Units) & (N/unit) \\
\cline { 2 - 9 } Post graduate students & 288 & 222.58 & 220 & 22.58 & 279 & 22.58 & 329 & 22.58 \\
Undergraduate students & 367 & 14.00 & 710 & 14.00 & 726 & 14.00 & 1023 & 14.00 \\
\hline
\end{tabular}

Table 3: Output Data (Method 2)

\subsection{Base Period Analysis}

The productivity literature suggests three main approaches in the use of base period analysis. The first concerns the use of an arbitrary base period, the second is the best base period approach. The third concerns the use of an average base period. The justification for the average base period can be found in the theory of central tendency (law of averages). In using the arbitrary base period, any base period could be chosen at will or randomly, so all the periods have equal chances of being chosen in this regard. For a rigorous analysis, consider all the three arbitrary base periods and calculated the productivity in each case. For the best base period, a comparison of the performance during each period is made. A baseline (period) productivity was calculated for each data set by determining the quantity and prices of the various input resources, and the grade points of all the students. Tables 2, 3 and 4 show the data used in this calculation.

A real calculation for the arbitrary base period involves the unbiased random choice of the base period for computation. For the case under investigation, four possible arbitrary base periods are possible (i.e. session 1 to session 4) and are so used for computation. The results of the base periods for the arbitrary approach are shown in tables 5 and 6 . From these, the average value base values could be computed. In selecting the best base period, the number of entries equal or above unity and the magnitude of such differences was considered. S1 was adjudged the best base period having $70.8 \%$ of values at least equal to unity, and 1,269.91 units as the magnitude of the differences. The worst base period is S3, having $37.5 \%$ of values at least equal to unity and 3.19 units above unity.

The mean value shown in table 6 is calculated based on the summation of the various inputs and output values over time divided by the total number of inputs or outputs concerned. This is used in the analysis for table 6. The significance of this lies in the ability of the researcher to monitor performance relative to the average value of input resources and the outputs. With this it is possible to understand which of these inputs or outputs are shrinking or growing. 


\begin{tabular}{|c|c|c|c|c|c|c|c|c|}
\hline \multirow[b]{2}{*}{ Description } & \multicolumn{2}{|c|}{ Session 1 (S1) } & \multicolumn{2}{|c|}{ Session 2 (S2) } & \multicolumn{2}{|c|}{ Session 3 (S3) } & \multicolumn{2}{|c|}{ Session 4 (S4) } \\
\hline & Qty & Price & Qty & Price & Qty & Price & Qty & Price \\
\hline \multicolumn{9}{|l|}{ Material (Expenses) } \\
\hline Printing \& Stationery & 231.3 & 1.0 & 48.45 & 1.0 & 310.8 & 1.0 & 161.1 & 1.0 \\
\hline Office supplies & 455.2 & 1.0 & 262.95 & 1.0 & 391.5 & 1.0 & 161.1 & 1.0 \\
\hline Labour & Man hrs & $\mathbb{N} / \mathrm{hr}$ & Man hrs & $\mathbb{N} / \mathrm{hr}$ & Man hrs & N/hr & Man hrs & N/hr \\
\hline Lecturer 1 & 69 & 23.32 & 720 & 23.52 & 480 & 37.15 & 840 & 22.35 \\
\hline Lecturer 2 & 450 & 36.18 & 300 & 57.13 & 540 & 33.41 & - & - \\
\hline Lecturer 3 & 330 & 4.19 & 450 & 26.39 & 390 & 32.06 & 450 & 29.24 \\
\hline Lecturer 4 & 240 & 45.42 & 390 & 29.42 & 390 & 30.97 & 720 & 17.66 \\
\hline Lecturer 5 & - & 15.00 & - & - & - & - & 540 & 15.00 \\
\hline Lecturer 6 & - & 15.00 & - & - & - & 15.00 & 450 & 15.00 \\
\hline Lecturer 7 & - & - & - & - & - & - & 270 & 15.00 \\
\hline Lecturer 8 & - & - & - & - & - & - & 120 & 15.00 \\
\hline Lecturer 9 & - & - & - & 15.00 & 210 & 15.00 & - & - \\
\hline Lecturer 10 & - & - & 90 & - & 180 & 15.00 & - & - \\
\hline Other Staff & 8400 & 3.55 & 8400 & 3.74 & 8400 & 3.93 & 8400 & 4.14 \\
\hline \multicolumn{9}{|l|}{ Capital } \\
\hline Office equipment & 41657.85 & 1.0 & 37029.2 & 1.0 & 32400.55 & 1.0 & 27771.9 & 1.0 \\
\hline Lab. Equipment & 18961.2 & 1.0 & 16854.4 & 1.0 & 14747.6 & 1.0 & 12640.8 & 1.0 \\
\hline Computer Equipment & 15075 & 1.0 & 13400 & 1.0 & 11725 & 1.0 & 10050 & 1.0 \\
\hline \multicolumn{9}{|l|}{ Others } \\
\hline Travelling Expenses & 947.70 & 1.0 & 880.30 & 1.0 & 1047.7 & 1.0 & 1435.9 & 1.0 \\
\hline Postage Expenses & 5.10 & 1.0 & 43.30 & 1.0 & - & - & - & - \\
\hline
\end{tabular}

Table 4: Input Data

\begin{tabular}{ccccccccc}
\hline Resource & \multicolumn{2}{c}{ Material } & \multicolumn{2}{c}{ Labour } & \multicolumn{2}{c}{ Capital } & \multicolumn{2}{c}{ Others } \\
\hline Base Period & M1 & M2 & M1 & M2 & M1 & M2 & M1 & M2 \\
\cline { 2 - 10 } S1 & 4.01 & 16.91 & 0.03 & 0.14 & 0.04 & 1.53 & 0.01 & 12.22 \\
S2 & 3.57 & 14.74 & 0.04 & 0.17 & 0.05 & 0.22 & 3.91 & 16.08 \\
S3 & 4.52 & 16.28 & 0.05 & 0.16 & 0.08 & 0.28 & 4.37 & 15.72 \\
S4 & 11.08 & 0.33 & 0.06 & 0.22 & 0.12 & 0.43 & 4.36 & 15.15 \\
\hline
\end{tabular}

Table 5: Static Productivity Indices (Method 1 (M1) and Method 2 (M2))

\subsection{Calculating Changes in Input and Output Values}

One aspect of this study is to examine the changes in the input and output values over the four periods considered. Here, two approaches were adopted. The first involves an arbitrary choice of a base period from which future values are compared. Usually the comparison involves the value obtained in the next period from the current value and dividing the result with the base period value. The next step in the computation usually involves keeping this base period constant while the period of comparison becomes the third session. The second approach 
follows the same procedure except that the base period often changes to the value in the next period.

\begin{tabular}{lccccccccc}
\hline \multicolumn{1}{c}{} & \multicolumn{2}{c}{ Material } & \multicolumn{2}{c}{ Labour } & \multicolumn{2}{c}{ Capital } & \multicolumn{2}{c}{ Others } \\
\hline \multirow{3}{*}{ Base Period } & Perio & M1 & M2 & M1 & M2 & M1 & M2 & M1 & M2 \\
S1 & ds & & & & & & & & \\
& S1 & 1.00 & 1.00 & 1.00 & 1.00 & 1.00 & 1.00 & 1.00 & 1.00 \\
& S2 & 0.89 & 0.87 & 1.33 & .21 & 1.25 & 0.14 & 391 & 1.32 \\
& S3 & 1.13 & 0.96 & 1.67 & 1.14 & 2.00 & 0.18 & 437 & 1.29 \\
S2 & S4 & 2.76 & 0.02 & 2.00 & 1.57 & 3.00 & 0.28 & 436 & 1.24 \\
& S1 & 1.12 & 1.15 & 0.75 & 0.82 & 0.80 & 6.95 & 0.003 & 0.76 \\
& S2 & 1.00 & 1.00 & 1.00 & 1.00 & 1.00 & 1.00 & 1.00 & 1.00 \\
& S3 & 1.27 & 1.10 & 1.25 & 0.94 & 1.60 & 1.27 & 1.13 & 0.98 \\
S3 & S4 & 3.10 & 0.02 & 1.50 & 1.29 & 2.40 & 1.95 & 1.12 & 0.94 \\
& S1 & 0.89 & 1.04 & 0.60 & 0.88 & 0.50 & 0.1 & 0.002 & 0.78 \\
& S2 & 0.79 & 0.91 & 0.80 & 1.06 & 0.63 & 0.02 & 0.89 & 0.78 \\
& S3 & 1.00 & 1.00 & 1.00 & 1.00 & 1.00 & 1.00 & 1.00 & 1.02 \\
& S4 & 2.45 & 0.02 & 1.20 & 1.38 & 1.50 & 1.54 & 1.00 & 1.00 \\
& S1 & 0.36 & 51.4 & 0.50 & 0.64 & 0.33 & 3.56 & 0.002 & 0.96 \\
& S2 & 0.32 & 44.67 & 0.67 & 0.77 & 0.42 & 0.51 & 0.90 & 0.81 \\
& S3 & 0.41 & 49.33 & 0.83 & 0.73 & 0.67 & 0.65 & 1.00 & 1.06 \\
& S4 & 1.00 & 1.00 & 1.00 & 1.00 & 1.00 & 1.00 & 1.00 & 1.04 \\
& Mean V1 & 0.69 & 1.40 & 0.60 & 0.82 & 057 & 2.47 & 0.003 & 0.83 \\
& S2 & 0.62 & 1.22 & 0.80 & 1.00 & 0.71 & 0.35 & 1.24 & 1.09 \\
& S3 & 0.78 & 1.35 & 1.00 & 0.94 & 1.14 & 045 & 1.38 & 1.06 \\
& S4 & 1.91 & 0.02 & 1.20 & 1.30 & 1.71 & 069 & 1.38 & 1.02 \\
\hline
\end{tabular}

Table 6: Dynamic Productivity Indices (Method 1 (M1) and Method 2 (M2))

\subsubsection{Input Resources}

In calculating the performance of the various input categories over time, the value for each component of the input resource type was obtained and then summed to represent the value used in computation (see table 4). For example, the material input resource performance utilizes the value of both printing and stationery and office supplies. Specific calculations are given below:

a. Material Input: Using the first approach the observed changes in the comparison of material input for period for sessions one and two show a negative value, that is a $54.64 \%$ drop. This is calculated form the change in value of both printing and stationery and office supplies for the two periods considered. For session 1, the total value was 686.5. It later dropped to 311.4. This drop in value suggests a drop in the number of graduating students at both the undergraduate and postgraduate levels. An increase of $2.34 \%$ and a drop of $53.05 \%$ followed 
afterwards. For the second approach the changes in material value was first noticed at $54.62 \%$, later increased to $125.53 \%$ and then dropped to $54.12 \%$.

b. Labour Input: The Naira value of the labour input when periods one and two were compared increased to $29.01 \%$ subsequently an increase of $1553.69 \%$ and $66.95 \%$ in the next two periods. For approach two, the result showed an initial increase to $29.01 \%$ followed by $1181.86 \%$ and $89.90 \%$ increase and decrease in the values of labour input respectively.

c. Capital Input: For the first approach the capital input increased by $189.29 \%$ over the initial period. This suggests an acquisition of capital assets such as labour equipment, office equipment, computer equipment in the period considered. A fall in the value of the next period to $153.13 \%$ was however, observed. It gradually decreased to $33.33 \%$. For the second approach an increase of $189.29 \%$ was initially observed. This dropped to $12.50 \%$ and increased to $76.66 \%$.

d. Other Expenses: Input An initial increase of 31.11\% was observed using the first approach this increased to $65.95 \%$ and subsequently to $127.41 \%$. For the second approach, the initial increase was $31.11 \%$ while increases of $26.55 \%$ and $37.03 \%$ were observed for the two subsequent periods.

\subsubsection{Output}

The first method shows an increase in output of $78.47 \%$ for period one, $76.22 \%$ and $68.95 \%$ increases for periods two and three respectively. For the second method increase of $78.47 \%$, $10.44 \%$ and $32.11 \%$ were observed.

\section{CONCLUSION AND FUTURE DIRECTIONS}

In this work, we apply the concept of productivity measurement to HEI since it is an effective performance improvement concept that seems beneficial to the HEI community. In particular an existing productivity measurement model and methodology is considered. The contribution to the field of industrial engineering and the wider higher education community lies in applying the model to a new environment (higher education institutions). This is an extension of knowledge since many of related studies in the literature have offered only qualitative descriptions of the concept, providing general guidelines. In addition, the few studies that have been empirical are limited to the use of an efficiency index. Unfortunately this is only a component of productivity which resulted in a partial indication of HEI's performance.

\subsection{The Lessons Learnt}

In this work, an ambitious step was taken in the direction of applying productivity measurement to HEI. We strongly view that it will be of great value if we can share the lessons learnt from the study. From a number of lessons, we have distilled a few. Firstly, we showed that it is possible to measure the productivity of individual lecturers in quantitative terms. The result obtained from this could be compare with that of annual performance evaluation and review (APER) form to establish fairness (or otherwise) the judgement of academic staff performance. We look forward to a period when the model will replace the existing measurement scheme used by universities, which contains some elements of subjectivity. 
Secondly, from the information obtained on the performance indices of individual lecturers, it is possible to identify non-performing staff. Hence corrective action could be taken to correct this anomaly.

Thirdly, in government-control led schools such as these which exist in most West African universities, the model presented is a valuable tool for evaluating the effect of taking other full time appointments on the productivity of academic staff soon after re-engagement. For example, a number of senior academic staff in the categories of senior lecturers and professors may sometimes go on secondment to order government institutions or organizations where their services are much needed at that time.

The new level of skill development will obviously show soon after re-engagement. The model could be useful in addressing this in future studies. For academic staff on sabbaticals, knowledge advancement during the sabbatical leave is expected. Thus, the new principles, techniques, methodologies and models learnt are expected to advance their knowledge and so reflect in the productivity measure. The same viewpoint applies to appointed vice chancellors, provosts, and deans of faculties who are expected to improve in both scholarly publication and administrative duties on returning to their former departments.

\subsection{The Challenges and Future Directions}

It is suggested that, though, many critical issues have been raised, and some answers offered, many issues are in need of empirical investigations and scrutiny. One of these issues is the application of fuzzy logic in measuring the quality and standard of the learning and teaching process. The strong reason for this is the model's inherent complexity and fuzziness in the measurement and estimation of its parameters that make the problem amenable to a fuzzy logic treatment. The quality and standard of learning and teaching employs a natural language that could be evaluated as "very good", "good”, "bad” and "very bad". As such it is subject to a fuzzy approach viewpoint.

The fuzzy approach to the learning and teaching problem offers a suitable framework for measuring higher education institution's productivity in its various aspects. The fuzzy approach as suggested for future studies should deal with the measurement of productivity when data are not precise. Thus, future modelling and empirical analysis to transform the human expertise into IF-THEN rules is suggested. This approach has the advantage of revealing semantic uncertainty with the associated non-specifying measure.

The application of multi-objective modelling to higher education institutions' productivity may contribute significantly to the literature in future studies. In many real world cases the concern may be the use of multiple objectives that could result in conflicts. Usually, the improvement of one objective may turn out to be detrimental to another if all the objectives are not considered simultaneously. A possible way to handle this is to use linear combination of the objective functions (LCOF) into one and then solving the single objective problem. Although some cases do not permit all conflicting objectives in a single criterion, the application of goal programming (GP) methodology developed by Charnes and others for solving linear programming problems may also expand the frontier of knowledge in higher education institutions' productivity. 
Another interesting direction to focus future research on may be the integration of quality our current work to form a hybrid model. The possible outcome may satisfy the long-awaited extension of the frontier of knowledge by adopting the wide-ranging manufacturing concept of productivity-quality marriage into studies in HEIs. While present a study that hopefully stimulates research in a new direction is presented it is necessary to state an important weakness of the proposal. The was only applied to a single university. The application of experimental design in future studies across a wide range of universities may be scientifically more acceptable than the present study. This may spark future empirical research of a comparative nature that may extend to regions across the globe. Although a case study of an academic department is used, comparative studies across departments in the same faculty may be interesting.

Administrators of higher education institutions may use information from this for budget preparations and approval. It may be useful to use such data also for the appointment of faculty members into the administrative functions of the universities. Knowledge from the present work may be useful for colleges, institutes and faculties since academic staff function in responsible positions under these divisions. This study is a useful means of furthering understanding in the field, and a motivator to researchers and professionals to give increased attention to some deep structures on the subject. For example it may be a good contribution to consider how to integrate some new ideas into the existing model.

An inquisitive mind may pose many questions: how can the quality of the students allowed on the programmes be brought into the productivity equation? Is there any significant difference between undergraduate and postgraduate students enrolled for programs for different locations in the world? An extension of the existing model may also incorporate the quality and the standard of the learning and teaching process. Ideas about the quality of the academic staff in the productivity equation may also be added.

If the proposal is accepted, it may be one of the solutions to the seemingly unattainable productivity reform programs in the education sector of some governments in West Africa and beyond. Such programs usually involve commitment of scarce resources and efforts but with little result. The failure of such programs may be due to the qualitative rather than quantitative approaches used for their implementation. This work is therefore an effort to correct such anomalies. There is therefore hope for governments if researchers could expand the concepts and ideas presented here.

The prescriptions possibly provide a description that is richer than the previous available perspectives in HEI productivity literature. It is hoped that future investigators will not only challenge and test our thoughts and ideas presented here, but also refine and extend them. Such efforts are critical to understanding the interacting effects of certain variables and, should foster an understanding of how to develop a balanced viewpoint of these relationships.

For those newly entering this area of study or those young in its pursuits, there is an exciting future filled with important discoveries. Good beginnings have been made, but there is more challenge in recognizing how far one has to go than in drawing satisfaction from past accomplishments. 


\section{REFERENCES}

[1] Alexander F.K. 2000. "The Changing Face of Accountability: Monitoring and Assessing Institutional Performance in Higher Education”, The Journal of Higher Education, 71(4).

[2] Billing D. 1998. "Quality Management and Organisational Structure in Higher Education”, Journal of Higher Education Policy and Management, pp 139.

[3] Brian Wilson, "Quality in Universities”, Journal of Higher Education Policy and Management, 18(2), pp 149-158.

[4] Charles-Owaba, O.E. 1989. “National Productivity Guideline”, National Productivity Centre, Nigeria, pp. 1-30.

[5] Cronje, M., Jacobs G.J., and Murdoch, N. 2002. "Rewarding Quality Teaching in Higher Education: The Evading Dream?” South African Journal of Higher Education, 16(2), pp 32-40.

[6] Donald J. G. and Denison D.B. 2001. "Quality Assessment of University Students: Student Perceptions of Quality Criteria”, The Journal of Higher Education, 73(4).

[7] Fairweather J.S. 2002. "The Mythologies of Faculty Productivity: Implications for Institutional Policy and Decision Making”, The Journal of Higher Education, 73(1).

[8] Gatfield T., Barker M., and Graham P. 1999. "Measuring Student Quality Variables and the Implications for Management Practices in Higher Education Institutions: an Australian and International Student Perspective, Journal of Higher Education Policy and Management, 21(2), 239.

[9] Kuh G.D. and Hu S. 2001. "Learning Productivity at Research Universities, The Journal of Higher Education, 72(1).

[10] Marsh H.W. and Hattie J. 2002. "The Relation Between Research Productivity and Teaching Effectiveness: Complementary, Antagonistic, or Independent Constructs”, The Journal of Higher Education, 73 (5).

[11] Marsh H.W., Rowe J.K., and Martin A. 2002. "Ph.D. Students' Evaluations of Research Supervision: Issues, Complexities, and Challenges in a Nationwide Australian Experiment in Benchmarking Universities”, The Journal of Higher Education, 73(4).

[12] Massaro V., "Institutional Responses to Quality Assessment: Developing Diversity”, Journal of Higher Education Policy and Management, 18(1), pp 35-44.

[13] Peterson M. W., and Marne K. Einarson M.K. 2001. "What are Colleges Doing About Student Assessment? Does It Make a Difference? The Journal of Higher Education, 72(6).

[14] Robst J. 2002. “Cost Efficiency in Public Higher Education Institutions”, The Journal of Higher Education, 73(3).

[15] Taylor B., and Harris G. 2002. "The Efficiency of South African Universities: A Study Based on the Analytical Review Technique”, South African Journal of Higher Education, 16 (2), pp 183- 192.

[16] Westhuizen L.J. 2002. "External and Internal Influences as Driving Forces and/or Stumbling-blocks in the Development of the South African Quality Assurance System Nationally as Well as Institutionally", South African Journal of Higher Education, 16 (2), pp 69-74. 


\section{ACKNOWLEDGEMENT}

The author wishes to acknowledge the contributions of Dr. O. E. Charles-Owaba, Department of Industrial and Production Engineering, University of Ibadan, Nigeria for initiating him into this research direction. 